\title{
Analysis of Differences in Students' Key Competencies in Relation to Types of College Admission Screening: Focused on the Case of C University
}

\author{
Jeoung-Suk Kwon'1)
}

\begin{abstract}
This study analyzed differences in students' key competencies in relation to types of college admission screening, using the case of $\mathrm{C}$ University. The school record-based college admission screening was initiated to normalize public education, but it is at the center of controversy. Selecting and educating talented students in each university according to the criteria will be the core of university education, so it is very meaningful to compare the differences in the core competencies of the students. The key competence examination test questionnaire developed by $\mathrm{C}$ university was used. The test questionnaire consisted of 67 questionnaire items, which were measured based on a total of 5 Likert scales. The students were divided into three groups according to college admissions. The survey was conducted online for the period from September 17 to September 21 in 2018. And an analysis was performed on the data of 2,697 students who participated in the key competence examination survey among those enrolled in the university as of 2018. In conclusion, the core competencies of students depended on the admission criteria that the university used as the selection criterion. In conclusion, the core competencies of students differed according to the admissions criteria in the criteria that the university used as the selection criteria. Therefore, the government should relax regulations on admission standards of each university and provide university autonomy so that each university can select and nurture competent students.
\end{abstract}

Keywords: College, Admission, Screening, School, Record-based, Key, Competencies, Educational, Inequality, Officer system

\section{Introduction}

The government has recently announced that it will increase the rate of general college admission, in consideration of the issue that college admission screening is believed to cause social inequality. The problem of college admission screening can be said to comprehensively reveal various problems associated with Korean educational practices. Education scholars in Korea shares a common interest, which is how education, one of the basic human rights, can

Received(September 18, 2019), Review Result(1st: October 7, 2019, 2nd: November 14, 2019), Accepted(January 30, 2020)

1) (Professor) 32244 College of Teaching Profession Chungwoon University, 25 Daehak-gil, Hongsung-Eup Chungnam, Korea

email: jskwon@chungwoon.ac.kr 
Analysis of Differences in Students' Key Competencies in Relation to Types of College Admission Screening: Focused on the Case of $C$ University

be equally provided to all members of society. As education is one of the essential means to achieve social success in Korea, equal distribution of education has been considered a key factor that determines equality in Korean society. The school record-based college admission screening was initiated to normalize public education, but it is at the center of controversy. Developed to replace the admission officer system, the school record-based comprehensive screening selects students by making comprehensive evaluations about non-subject areas, such as club activities, prizes, volunteer work and reading activities, and confers an advantage on students who worked hard during their school life. In the 2019 school year, a total of 84,860 students were selected through the school-record screening method, which has been criticized as "blind screening." The figure was similar to the 2018 school year $(32.3 \%)$ and higher than the school year 2017 (29.5\%). Particularly, ten universities in Seoul, so-called "in-Seoul universities," selected 23,816 students through rolling admissions in 2019 and 14,632 students among them were selected through the school record-based comprehensive screening method $(61.4 \%)[1]$. Seoul National University selected $79.6 \%$ of the total freshmen for the 2020 school year through the school record-based comprehensive screening method, and four out of every ten students are selected through the school record-based comprehensive screening method at 15 major universities in Seoul[2].

Universities establish their concept of talented individuals and try to select students who have the potential to become the talented individuals they pursue. As we enter the knowledge-based society and our society transforms into a society based on mutual cooperation and networking in which individuals' abilities are valued, we need to establish a new paradigm of higher education in order to secure national competitiveness. It is a key issue of the times to educate and secure outstanding and creative top-level human resources in order to obtain a national competitive edge. At a time when the globalization of knowledge accelerates, higher education should assume the social role to develop a knowledge-production group's ability to create and use new knowledge and technology[3]. The OECD defines competencies as general ability necessary to improve the quality of human life, and in Korea, many studies on competencies have been performed. The 2015 Revised National Curriculum of Korea suggests six key competencies: "self-management competency," "knowledge and information processing competence," "creative thinking competence," "aesthetic sensibility competence," "communication skill competence," and "civic competency."[4] And Korean universities determine key competencies that accord with their concept of talented individuals and run curriculums focused on the key competencies.

At this point in time when there is growing controversy over the college entrance exam 
system, it seems critical to examine the characteristics of students according to each type of college admission screening in order to determine the correct or appropriate direction of the future college entrance exam system. Previous studies on students' characteristics according to each type of college admission screening were largely performed in relation to their adaptation to college life and comparison of their academic achievement[5-8]. Although a study was recently performed to analyze differences in students' academic achievement and key competencies according to the type of admission screening at a university[9], studies analyzing such differences are rarely performed. Against this backdrop, this study intends to present a case that can show whether universities select students with potential that accords with their educational ideals and purposes by analyzing differences in university students' key competencies according to the type of college admission screening.

\section{Research Methods and Content}

\subsection{Research Subjects and Composition of the Test Questionnaire}

Key competencies decided by C University were measured using the test questionnaire developed by the university, and the key competencies include seven domains: creative problem solving, practical expert knowledge, global competitiveness, value judgment, self-enrichment, community spirit, and cooperative communication. The domain of creative problem solving has two sub-domains, which are creative thinking and creative attitude, and there are six questionnaire items to measure creative thinking and three items to measure creative attitude. Practical expert knowledge is measured by ten questionnaire items, six to measure the quest for knowledge and four to measure the ability to use knowledge. The domain of global competitiveness consists of two sub-domains, which are the ability to accept multi-culturalism and the ability to be aware of globalization, each measured by three questionnaire items. The domain of value judgment is measured by a total of 15 questionnaire items within three sub-domains: social responsibility, respect \& consideration and sense of ethics. There are five items in each of these sub-domains. The domain of self-enrichment has three sub-domains: life planning \& executive ability, self-regulation ability, and self-directed learning ability. These sub-areas are measured by six, three and three questionnaire items, respectively. The domain of community spirit is measured by four questionnaire items of voluntary participation and sharing and three items of altruistic help. The domain of cooperative communication consists of two sub-domains, which are delivery \& expressive ability 
Analysis of Differences in Students' Key Competencies in Relation to Types of College Admission Screening: Focused on the Case of $C$ University

and acceptance \& cooperation ability, each measured by four items. Thus, the test questionnaire consists of a total of 67 questionnaire items, which are measured on a five-point Likert scale, ranging from "not at all" (1) to "very much" (5).

As for the reliability of the survey tool, the overall Cronbach's alpha of the questionnaire was .976. The Cronbach's alpha coefficients of all domains were as follows. They were 954 for value judgment, .913 for creative problem solving, .926 for self-enrichment, .909 for community spirit, .839 for global competitiveness, .916 for practical expert knowledge, and 925 for cooperative communication.

\subsection{Research Methods}

To identify differences in the key competencies between groups, an analysis of differences in the key competencies and sub-domain abilities was conducted in relation to types of college admission screening. To find out if there are differences in the mean scores of the key competencies and sub-domain abilities, SPSS 23 was used to analyze differences in the mean scores and interpret the meaning. Statistics used in the analysis include frequency, mean, standard deviation and ANOVA.

\section{Results of the Research}

Among the core competencies, there were three items that showed statistically significant differences by admission. With regard to differences in relation to types of college admission screening, students admitted to the university through school record-based comprehensive screening scored a mean score of 3.61 on "community spirit," which was higher than those of students admitted through other types of college admission screening at a statistically significant level $(p=.015)$. There were no statistically significant differences in other key competencies.

On the item "I voluntarily participate in events of my department and club activities," under the sub-domain of "voluntary participation and sharing," the mean score of all groups was very low at 3.3. But students admitted through school record-based comprehensive screening scored a mean score of 3.55, which was higher compared to those admitted through general screening (3.28) and other types of screening (3.33) at a statistically significant level ( $p=.004)$. The results of the post-test also showed a higher mean score of those admitted through school record-based comprehensive screening. 
On the item "When there is something to be done in my community, I voluntarily step forward to do it," the mean score of all groups was low at 3.4. But students admitted through school record-based comprehensive screening scored a mean score of 3.64, which was higher compared to those admitted through general screening (3.37) and other types of screening (3.44) at a statistically significant level $(\mathrm{p}=.000)$. The results of the post-test also showed a higher mean score of those admitted through school record-based comprehensive screening.

[Table 1] Average Differences in Core Competencies by Admissions(statistically significant in post-test)

\begin{tabular}{|c|c|c|c|c|c|c|}
\hline Core competencies/types & f screening & $\bar{M}$ & S.D & $\mathrm{F}$ & $\mathrm{p}$ & Scheffe \\
\hline \multirow{4}{*}{ Community spirit } & general scr. & 3.46 & .711 & \multirow{4}{*}{4.178} & \multirow{4}{*}{.015} & \multirow{4}{*}{$\begin{array}{l}\text { gen, other } \\
\text { <record-ba } \\
\quad \text { sed }\end{array}$} \\
\hline & record-based scr. & 3.61 & .703 & & & \\
\hline & other type of scr. & 3.52 & .674 & & & \\
\hline & Total & 3.48 & .707 & & & \\
\hline \multirow{4}{*}{$\begin{array}{l}\text { I voluntarily participate in } \\
\text { events of my department and } \\
\text { club activities }\end{array}$} & general scr. & 3.28 & 1.030 & \multirow{4}{*}{5.638} & \multirow{4}{*}{.004} & \multirow{4}{*}{$\begin{array}{l}\text { gen, other } \\
\text { <record-ba } \\
\quad \text { sed }\end{array}$} \\
\hline & record-based scr. & 3.55 & .953 & & & \\
\hline & other type of scr. & 3.33 & 1.011 & & & \\
\hline & Total & 3.30 & 1.024 & & & \\
\hline \multirow{4}{*}{$\begin{array}{l}\text { When there is something to be } \\
\text { done in my community, I } \\
\text { voluntarily step forward to do } \\
\text { it }\end{array}$} & general scr. & 3.37 & .876 & \multirow{4}{*}{8.300} & \multirow{4}{*}{.000} & \multirow{4}{*}{$\begin{array}{l}\text { gen, other } \\
\text { <record-ba } \\
\quad \text { sed }\end{array}$} \\
\hline & record-based scr. & 3.64 & .874 & & & \\
\hline & other type of scr. & 3.44 & .845 & & & \\
\hline & Total & 3.40 & .874 & & & \\
\hline
\end{tabular}

There was no statistically significant difference in post-test between core competencies, but each of the nine items showed a difference in the mean value.

As for differences in the mean scores of sub-domain abilities, students admitted through other types of screening scored a mean score of 3.67 on "life planning \& executive ability," which was higher than the mean scores of students admitted through record-based comprehensive screening (3.65) and general screening (3.57) at a statistically significant level $(p=.03)$. Also, In terms of self-regulation ability and self-directed learning ability, students admitted through school record-based comprehensive screening scored mean scores slightly higher than those of students admitted through general screening and other types of screening. With regard to the "ability to use knowledge" under the domain of practical expert knowledge, the mean score of students admitted through other types of screening was 3.63, which was higher compared to those admitted through record-based comprehensive screening (3.63) and general screening (3.54) at a statistically significant level $(p=.044)$.

On the item "I have a comparatively clear career goal," in the sub-domain of life planning \& executive ability, students admitted through school record-based comprehensive screening scored a mean score of 3.61, which was higher compared to those admitted through other types of screening (3.60) and general screening (3.48) at a statistically significant level ( $\mathrm{p}=.031)$. 
Analysis of Differences in Students' Key Competencies in Relation to Types of College Admission Screening: Focused on the Case of $C$ University

On the item "I have a plan for my career and job and constantly carry out the plan," students admitted through other types of screening scored a mean score of 3.52, which was higher compared to those admitted through school record-based comprehensive screening (3.48) and general screening (3.40) at a statistically significant level $(\mathrm{p}=.048)$. On the item "I know what I have to do to make my dream come true," students admitted through other types of screening scored a mean score of 3.7, which was higher compared to those admitted through general screening and school record-based comprehensive screening (3.57) at a statistically significant level $(\mathrm{p}=.043)$. On the item "I am learning to gain knowledge and skills to get a job I want," students admitted through other types of screening scored a mean score of 3.77 , which was higher compared to those admitted through school record-based comprehensive screening (3.74) and general screening (3.64) at a statistically significant level $(\mathrm{p}=.010)$.

On the item "When there is something to be done in my community, I voluntarily step forward to do it," the mean score of all groups was low at 3.4. But students admitted through school record-based comprehensive screening scored a mean score of 3.64, which was higher compared to those admitted through general screening (3.37) and other types of screening (3.44) at a statistically significant level $(\mathrm{p}=.000)$.

On the item "When there is an event in my department or when I participate in club activities, I actively help my friends, juniors and seniors" in the sub-domain of "altruistic help," students admitted through school record-based comprehensive screening scored a mean score of 3.61, which was higher compared to those admitted through other types of screening (3.51) and general screening (3.45) at a statistically significant level $(p=.049)$.

[Table 2] Average Difference in Items by Admissions(statistically non-significant in post-test)

\begin{tabular}{|c|c|c|c|c|c|}
\hline \multicolumn{2}{|c|}{ Core competencies/types of screening } & $\mathrm{M}$ & S.D & $\mathrm{F}$ & $\mathrm{p}$ \\
\hline \multirow{4}{*}{ Life planning \& executive ability } & general scr. & 3.57 & .722 & \multirow{4}{*}{3.497} & \multirow{4}{*}{.030} \\
\hline & record-based scr. & 3.64 & .701 & & \\
\hline & other type of scr. & 3.67 & .701 & & \\
\hline & Total & 3.59 & .719 & & \\
\hline \multirow{4}{*}{ Ability to use knowledge } & general scr. & 3.55 & .669 & \multirow{4}{*}{3.119} & \multirow{4}{*}{.044} \\
\hline & record-based scr. & 3.61 & .623 & & \\
\hline & other type of scr. & 3.63 & .690 & & \\
\hline & Total & 3.56 & .669 & & \\
\hline \multirow{4}{*}{$\begin{array}{c}\text { I try to apply expert knowledge or skills to } \\
\text { real situations }\end{array}$} & general scr. & 3.58 & .764 & \multirow{4}{*}{3.714} & \multirow{4}{*}{.025} \\
\hline & record-based scr. & 3.70 & .725 & & \\
\hline & other type of scr. & 3.67 & .762 & & \\
\hline & Total & 3.60 & .762 & & \\
\hline \multirow{2}{*}{$\begin{array}{l}\text { I have an interest in the multi-cultural } \\
\text { family issue in my community }\end{array}$} & general scr. & 3.22 & .890 & \multirow{2}{*}{3.266} & \multirow{2}{*}{.038} \\
\hline & record-based scr. & 3.40 & .825 & & \\
\hline
\end{tabular}




\begin{tabular}{|c|c|c|c|c|c|}
\hline & other tyme of scr & 322 & 072 & & \\
\hline & Total & 324 & 891 & & \\
\hline \multirow{4}{*}{ I have a comparatively clear career goal } & general scr. & 3.48 & .926 & \multirow{4}{*}{3.474} & \multirow{4}{*}{.031} \\
\hline & record-based scr. & 3.61 & .911 & & \\
\hline & other type of scr. & 3.60 & .886 & & \\
\hline & Total & 3.51 & .921 & & \\
\hline \multirow{4}{*}{$\begin{array}{l}\text { I have a plan for my career and job and } \\
\text { constantly carry out the plan, }\end{array}$} & general scr. & 3.40 & .904 & \multirow{4}{*}{3.040} & \multirow{4}{*}{.048} \\
\hline & record-based scr. & 3.48 & .898 & & \\
\hline & other type of scr. & 3.52 & .832 & & \\
\hline & Total & 3.42 & .896 & & \\
\hline \multirow{4}{*}{$\begin{array}{l}\text { I know what I have to do to make my } \\
\text { dream come true }\end{array}$} & general scr. & 3.57 & .879 & \multirow{4}{*}{3.161} & \multirow{4}{*}{.043} \\
\hline & record-based scr. & 3.57 & .835 & & \\
\hline & other type of scr. & 3.70 & .879 & & \\
\hline & Total & 3.59 & .877 & & \\
\hline \multirow{4}{*}{$\begin{array}{l}\text { I am learning to gain knowledge and skills } \\
\text { to get a job I want }\end{array}$} & general scr. & 3.64 & .843 & \multirow{4}{*}{4.580} & \multirow{4}{*}{.010} \\
\hline & record-based scr. & 3.74 & .824 & & \\
\hline & other type of scr. & 3.77 & .837 & & \\
\hline & Total & 3.66 & .842 & & \\
\hline \multirow{4}{*}{$\begin{array}{l}\text { When there is an event in my department } \\
\text { or when I participate in club activities, I } \\
\text { actively help my friends, juniors and seniors }\end{array}$} & general scr. & 3.45 & .886 & \multirow{4}{*}{3.020} & \multirow{4}{*}{.049} \\
\hline & record-based scr. & 3.61 & .837 & & \\
\hline & other type of scr. & 3.51 & .839 & & \\
\hline & Total & 3.47 & .878 & & \\
\hline
\end{tabular}

\section{Conclusion}

In October 2004, the Ministry of Education confirmed and announced the "2008 College Entrance Exam Improvement Plan," prepared by the Presidential Committee on Education Innovation in a bid to normalize public education and solve private education problems. As a result, an admission officer system was implemented to change the college entrance system, which heavily relied on students' scores in the national college entrance exam, and to make the exam score merely a qualification exam, not a factor to assess students for college entrance. In other words, the Ministry of Education had universities select students based on students' school records, interview and non-subject areas. A total of ten universities selected students through the admission officer system in 2007, and the number of universities that adopted the admission officer system increased to 16 in 2008 and 45 in 2009. In August 2013, the Park Geun-hye administration announced the "College Admission Screening Simplification and College Entrance System Development Plan," which was to be implemented in the college entrance exam for the 2015 school year, and changed the name 'the admission officer screening' to 'school record-based comprehensive screening'. As it was pointed out that the changed college entrance exam caused excessive competition among students to improve their school 
Analysis of Differences in Students' Key Competencies in Relation to Types of College Admission Screening: Focused on the Case of $C$ University

records through outside-school activities, the college entrance exam was changed to focus on assessment of school activities. Still the college entrance exam included such things as club activities, student council activities, volunteer work, a letter of self-introduction, a brief research paper and an in-school competition. In 2018, the Moon Jae-in administration announced the "School Record-Based Comprehensive Screening and Fairness Strengthening Plan." As a result, a brief research paper will be excluded from school records, beginning in 2022. And only one prize per semester can be recorded in school records[10].

As the college entrance system changed with the Park Geun-hye administration, the admission officer screening was renamed school record-based comprehensive screening. And this type of screening has consistently increased. The recent change toward knowledge technology, which is called the fourth industrial revolution, requires talented individuals with the creative ability to solve problems. In response to such social demand, universities set key competencies and educate talented students accordingly.

The case of C University can be summarized as follows.

First, key competencies with the highest mean scores were "value judgment (3.88)," "cooperative communication (3.68)," "practical expert knowledge (3.64)" and "creative problem solving (3.63)" in descending order, and "global competitiveness (3.39)" had the lowest mean score.

Second, with regard to differences in relation to types of college admission screening, students admitted to the university through school record-based comprehensive screening scored a mean score of 3.61 on "community spirit," which was higher compared to those admitted through other types of college admission screening (3.51) and general screening (3.46). There were statistically significant differences between groups $(\mathrm{p}=.015)$

Third, as for sub-domain abilities under the key competencies, students admitted through other types of screening scored a mean score of 3.63 on the "ability to use knowledge" under the domain of "practical expert knowledge," which was higher compared to those admitted through record-based comprehensive screening (3.61) and general screening (3.54) at a statistically significant level $(\mathrm{p}=.044)$. And students admitted through other types of screening scored a mean score of 3.67 on "life planning \& executive ability" under the domain of "self-enrichment," which was higher compared to those admitted through record-based comprehensive screening (3.65) and general screening (3.57) at a statistically significant level $(p=.03)$.

Fourth, in the sub-domain of "voluntary participation and sharing" under "community spirit," students admitted through school record-based comprehensive screening scored a mean 
score of 3.57, which was higher compared to those admitted through other types of screening (3.44) and general screening (3.38) at a statistically significant level $(p=.002)$. The results of the post-test also showed a higher mean score of those admitted through school record-based comprehensive screening at a statistically significant level.

Fifth, regarding differences in the mean scores of questionnaire items to measure the key competences, students admitted through school record-based comprehensive screening scored a mean score of 3.7 on the questionnaire item "I try to apply expert knowledge or skills to real situations," which was higher compared to those admitted through general screening (3.58) and other types of screening (3.67) at a statistically significant level $(p=.025)$. But the results of the post-test did not show statistically significant differences. This shows that students, admitted through school record-based comprehensive screening, make more efforts to apply expert knowledge and skills they are learning in real situations.

The results of this study are similar in some aspects to the results of the study performed by Gu Yun-jeong, Kim Tae-seon and Hong Seon-yeon (2019)[8]. The study (2019) conducted a survey on students in the first year of the Department of Nursing Science. The results of the survey found no significant differences in students' competencies in relation to types of college admission screening. But the study reported that students admitted through school record-based comprehensive screening had slightly higher scores than those admitted through school record-based subject screening on all the six competencies: humanity ability, humanism ability, self-direction ability, practical job ability, creative ability and global ability[9].

This result is considered to be attributable to the use of the key competency examination tool that was developed by the university to reflect its concept of talented individuals, foundation ideology and education purposes, and the study reported that school record-based comprehensive screening is effective from the perspective of selecting students in a way that accords with universities' concept of talented individuals and educational purposes through the liberalization of college entrance exams. In previous studies, key competencies were identified and analyzed in relation to types of college admission screening and it was found that the admission officer screening method reflected key competencies better than the rolling admission screening method[11]. Against a background where the educational outcomes sought by universities should fundamentally change from placing an overwhelming emphasis on the attainment of mere grades and scores to the promotion of competencies, the school record-based comprehensive screening allows universities to select students based on the educational goals, concept of talented individuals and key competencies they wish to promote and pursue. In this sense, the school record-based comprehensive screening enables a better 
Analysis of Differences in Students' Key Competencies in Relation to Types of College Admission Screening: Focused on the Case of $C$ University

selection of students with potentials and achieves good results in this regard[9].

This study may have limitations because it analyzed the case of just one university. But this study concludes that school record-based comprehensive screening should be properly maintained from the perspective of pursuing educational equality by guaranteeing universities' rights to select students and operating various college admission systems. And further studies need to be conducted to empirically identify differences in students' key competencies and improvement in their key competencies in relation to types of college admission screening.

\section{References}

[1] https://news.joins.com/article/23454906, Apr 30 (2019)

[2] http://www.edujin.co.kr/, Nov 7 (2019)

[3] S.D. Choi, S. E. Lee, K.H.Kim, O. H.Lee, Y.S. Choi, Promoting Core Competency Education and Building Innovative Learning Ecosystems for Fostering Talent for the Future(II), Korean Educational Development Institute, (2014)

[4] https://moe.go.kr/boardCnts/view.do?boardID=316 Feb 26 (2016)

[5] S.B. Oh, Analysis of Differences in Adaptation to College Life among University Admission Type, Korean Education Inquiry, (2017), Vol.35, No.2, pp.35-52, 10.22327/kei.2017.35.2.035.

[6] S.Y. Park, J.Y Kim, Analysis of Longitudinal Impact on Student Adaptation to College and Academic Achievement of College Admission System, Korean Journal of Educational Administration, (2018), Vol.36, No.5, pp.323-353.

[7] J.H. Oh, J.Y. Jung, Y.H. Hong, S.G.Park, S. Kim, A Study on the Performance Evaluation of the College-Entrance Processes, The Korean Journal of Applied Statistics (2010), Vol.23, No.5, pp.987-996, https://doi.org/10.5351/KJAS.2010.23.5.987.

[8] H.Y. Lee, M.H Jo, H.W. Lee, Relationships among High School grade, the College Scholastic Ability Test Scores, and University Academic Achievement by Types of Admission : A Case of A University, The Journal of Career Education Research, The Korean Society for the Study of Career Education, (2016), Vol.29, No.2, pp.109-127.

[9] Y.J Koo, T.S. Kim, S.Y. Hong, A Study of Academic Achievement and Core Competence according to University Admission Types in Nursing Students Journal of the Korea Society of Computer and Information, The Korean Society Of Computer And Information, (2019), Vol.24, No.7, pp.117-123, https://doi.org/10.9708/jksci.2019.24.07.117.

[10] https://www.namu.wiki/w/\%EC\%9E\%85\%ED\%95\%99\%EC\%82\%AC\%EC\%A0\%95\%EA\%B4\%80\%EC\%A0\%9C, Dec 23 (2019)

[11] J.I. Lee, A Study on University Students' Essential Skills and University Admission Methods, Journal of Agricultural Education and Human Resource Developmnt, (2012), Vol.44, No.2, pp.73-96, DOI: 10.23840/agehrd.2012.44.2.73. 